\title{
Trichoderma lixii (IIIM-B4), an endophyte of Bacopa monnieri L. producing peptaibols
}

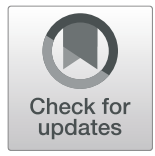

Meenu Katoch ${ }^{1 * \dagger} \mathbb{D}$, Deepika Singh ${ }^{2^{*} \dagger}$, Kamal K. Kapoor ${ }^{3}$ and R. A. Vishwakarma ${ }^{4}$

\begin{abstract}
Background: Exploration of microbes isolated from north western Himalayas for bioactive natural products.

Results: A strain of Trichoderma lixii (IIIM-B4) was isolated from Bacopa monnieri L. The ITS based rDNA gene sequence of strain IIIM-B4 displayed 99\% sequence similarity with different Trichoderma harzianum species complex. The highest score was displayed for Hypocrea lixii strain FJ462763 followed by H. nigricans strain NBRC31285, Trichoderma lixii strain CBS 110080, T. afroharzianum strain CBS124620 and Trichoderma guizhouense BPI:GJS 08135 respectively. Position of T. lixii (IIIM-B4) in phylogenetic tree suggested separate identity of the strain. Microbial dynamics of T. lixii (IIIM-B4) was investigated for small peptides. Medium to long chain length peptaibols of 11 residue (Group A), 14 residue (Group B) and 17 residue (Group C) were identified using Matrix Assisted Laser Desorption/lonization-Time of Flight (MALDI-TOF) mass spectrometer. Optimization is undeniably a desideratum for maximized production of desirable metabolites from microbial strain. Here optimization studies were carried out on T. lixii (IIIM-B4) using different growth media through Intact Cell Mass Spectrometry (ICMS). A multifold increase was obtained in production of 11 residue peptaibols using rose bengal medium. Out of these, one of them named as Tribacopin AV was isolated and sequenced through mass studied. It was found novel as having unique sequence Ac-Gly-Leu-Leu-Leu-Ala-Leu-Pro-Leu-Aib-Val-Gln-OH. It was found to have antifungal activity against Candida albicans $(25 \mu \mathrm{g} / \mathrm{mL}$ MIC).

Conclusion: In this study, we isolated a strain of T. lixii (IIIM-B4) producing medium and long chain peptaibols. One of them named as Tribacopin AV was found novel as having unique sequence Ac-Gly-Leu-Leu-Leu-Ala-Leu-Pro-LeuAib-Val-Gln-OH, which had antifungal properties.
\end{abstract}

Keywords: Intact cell mass spectrometry, Bacopa monnieri, Optimization, Peptaibols, Matrix assisted laser desorption/ionisation-time of flight (MALDI-TOF) mass spectrometer

\section{Background}

Endophytic microorganisms have immense potential for producing diverse array of small novel secondary metabolites with key biological activities [1-3]. These metabolites have potential to be used as drugs [4]. The North western Himalayas are bestowed with rich plant and microbial biodiversity. Constant metabolic and ecological interactions happening in the ecosystem implies the biological diversity [5]. This biodiversity can lead to

\footnotetext{
* Correspondence: meenusamiksha@rediffmail.com; mkatoch@iiim.ac.in; dsingh@iiim.ac.in; dsingh@iiim.res.in

${ }^{\dagger}$ Meenu Katoch and Deepika Singh contributed equally to this work.

${ }^{1}$ Microbial Biotechnology Division, Indian Institute of Integrative Medicine, Canal Road, Jammu 180001, India

${ }^{2}$ Quality Control and Quality Assurance Division, Indian Institute of Integrative Medicine, Canal Road, Jammu 180001, India

Full list of author information is available at the end of the article
}

the discovery of new chemical entities. Much of the microbial diversity existing in north western Himalayas is unexplored or underexplored. B. monnieri (L.) belonging to this region is also unexplored.

B. monnieri (L.) Pennell (Scrophulariaceae) commonly known as Brahmi, has been used for centuries in Ayurvedic medicine either singly or in combination with other herbs for treating gastrointestinal and neurologic disorders such as Alzheimer's disease, improving memory, anxiety, attention deficit-hyperactivity disorder (ADHD) etc. [6, 7]. It is also known for curing disorders like anemia, ulcers, leprosy, inflammation, enlarged spleen, ascites and tumors. Prior studies have proved that its medicinal effects have been attributed to saponins (bacosides, bacopasides, bacopasponins) [8]. It also has antidepressant, anti-inflammatory, antioxidant

(c) The Author(s). 2019 Open Access This article is distributed under the terms of the Creative Commons Attribution 4.0 International License (http://creativecommons.org/licenses/by/4.0/), which permits unrestricted use, distribution, and 
and hepatoprotective properties [9-12]. Because of the medicinal properties of the plant, it was selected for the isolation purpose.

Fungi of the Trichoderma genus, notably Trichoderma harzianum have been extensively used as biopesticides (against deleterious seed and soil borne pathogens) and biofertilizers [13]. The mechanism of biocontrol includes mycoparasitism, antibiosis, competition and cell wall-lytic enzyme activity, while mechanism of biofertilizer includes enhancement of plant growth, acquisition of soil nutrients and induction of plant defense response respectively [14-18]. During interaction with plant, they produce astonishingly high number and structurally diverse secondary metabolites, which include polyketides, terpenoids, steroids, gliotoxins, gliovirins, peptides, proteins and low molecular weight compounds with antibiotic properties [19-23].

Trichoderma is also known for peptaibol production $[24,25]$. Varieties of peptaibols have been reported from Trichoderma spp. [26-28]. From the pharmacological perspective, peptaibols exhibit variety of bioactivities with claims of antibacterial, antifungal, anticancer, immunosuppressive, antimycoplasmic, antitrypanosomal and wound healing properties, while from agricultural perspective, their role in biocontrol and induced disease resistance has also been reported [27-34]. Thus, they have potential to be used in medicine, agriculture and industry $[35,36]$.

Various peptaibols have been identified using Intact Cell Mass Spectroscopy (ICMS), a prominent fast analytical technique in biological sciences because sample requirement is minimum, sample preparation is simple (dried solid samples are workable) and automated mass analysis is possible within a short span of time. This technique is already in use for identification of different microbial species/strains, peptaibols from fungi and recently used for monitoring the fermentation process of Penicillin $\mathrm{V}$ and for optimizing the peptaibol production [37-41].

The current study reports a new strain of T. lixii isolated from B. monnieri producing medium and long chain peptaibols identified through ICMS by MALDI TOF mass spectrophotometer and MS/MS studies. It also includes optimization of best possible growth conditions for further scale up and isolation of novel secondary metabolites.

\section{Methods}

\section{Reagents}

$\alpha$-cyano-4-hydroxycinnamic acid (CHCA), 2,5-dihydroxybenzoic acid (DHB), Trifluroacetic acid (THF) were acquired from Sigma Aldrich, India. Solvents such as acetonitrile, ethyl acetate, dichloromethane and methanol were obtained from Thermo Fisher, India. Media components were purchased from Himedia, India.

\section{Isolation of a strain of IIIM-B4}

Fully matured wild $B$. monnieri plants were collected randomly between March - April, 2013 from Jammu and Kashmir (altitude of about $32.73^{\circ} \mathrm{N} 74.87^{\circ} \mathrm{E}$ ), India as per the Institute's guidelines and were authenticated by the taxonomist of the Institute based on its characteristic features. The fungal endophytes were isolated from B. monnieri using the method described by Strobel and Daisy [42] and Katoch et al. [43, 44]. IIIM-B4, an endophyte isolated from this plant was chosen for this study.

\section{Morphological, Microscopical and molecular identification of strain IIIM-B4}

Strain IIIM-B4 was characterized on the basis of colony and microscopic features such as the structure of conidiophore, conidia and chlamydospore.

It was identified through ITS based DNA sequencing using ITS1 and ITS4 primers [36-39]. The culture has been submitted to Sir R.N. Chopra, Microbial Resource Centre, Jammu, India with accession no MRCJ-512. Fungal mycelia grown in potato dextrose broth for 5 days were filtered through filter paper (Whatman no-3). The mycelium $(500 \mathrm{mg})$ was then crushed in liquid nitrogen to make fine powder and genomic DNA was extracted [45-48]. Briefly, powdered mycelium was transferred to $5 \mathrm{~mL}$ of extraction buffer and vortexed thoroughly. The samples were incubated in water bath at $65^{\circ} \mathrm{C}$ for 30 min with intermittent mixing. The tubes were centrifuged at $10,000 \mathrm{~g}$ for $5-10 \mathrm{~min}$ followed by extraction of aqueous layer with chloroform:isoamyl alcohol $(24,1)$. Aqueous layer was collected and DNA was precipitated with $2.5-3 \mathrm{~V}$ of absolute ethanol in presence of $1 / 10$ th volume of sodium acetate. Tubes were inverted slowly to mix the contents and centrifuged at $8000 \mathrm{~g}$ for $20 \mathrm{~min}$ at $4{ }^{\circ} \mathrm{C}$. White/transparent pellets thus obtained were washed with ice cold $70 \%$ ethanol followed by air drying. Dried pellets were dissolved in $20 \mu \mathrm{L}$ of water (molecular biology grade).

The ITS regions of fungi were amplified with universal ITS1 and ITS4 primers using polymerase chain reaction (PCR) [49]. The PCR reaction mix $(20 \mu \mathrm{L})$ contained $1 \times$ PCR buffer containing $15 \mathrm{mM} \mathrm{MgCl} 2,200 \mathrm{mM}$ of each dNTP, forward and reverse primer $10 \mathrm{pmol}$ (Sigma, USA), $10 \mathrm{ng}$ of DNA and $0.1 \mathrm{U}$ Taq DNA polymerase (Promega, US). The PCR conditions consisted of initial denaturation at $95^{\circ} \mathrm{C}$ for $5 \mathrm{~min}$ followed by 30 cycles of $94{ }^{\circ} \mathrm{C}$ for $30 \mathrm{~s}$ (denaturation), $55^{\circ} \mathrm{C}$ for $1 \mathrm{~min}$ (annealing), $72{ }^{\circ} \mathrm{C}$ for $1 \mathrm{~min}$ (extension) and $72^{\circ} \mathrm{C}$ for $10 \mathrm{~min}$ (final extension) [46-48]. The PCR products were resolved on $2 \%(\mathrm{w} / \mathrm{v})$ agarose gel at $80 \mathrm{~V}$ followed by purification 
using gel extraction kit (Qiagen, USA). The purified product was sequenced using Big Dye Terminator sequencing kit (v. 3.1, Applied Biosystems) using an automatic DNA Sequencer (310 Genetic Analyser, Applied Biosystems, Foster city, CA). The obtained sequence was analyzed by BLASTn tool of NCBI [www. ncbi.nlm.nih.gov/Blast.cgi] to identify the strain [50].

Besides, the ITS sequences were compared to a specific database for Trichoderma using Trich OKEY2 program, which available online from the International Subcommission on Trichoderma and Hypocrea Taxonomy (ISTH, www.isth.info) [51].

\section{Phylogenetic evaluation of strain IIIM-B4}

For phylogenetic characterization, T. lixii (IIIM-B4) sequence (Gene Bank accession number KF6839108) and relevant downloaded sequences (FJ462763, JN943368, NR_131264, NR137304, KP115286, AF057584, KU729029, JQ745258, KC171340, NR130668, AY380909) were aligned using Clustal W-pairwise sequence alignment of the EMBL nucleotide Sequence Database [46-48]. The sequence alignments were trimmed and verified by the MUSCLE (UPGMA) algorithm [52] using MEGA4 software [53]. The phylogenetic tree was reconstructed and the evolutionary history inferred using the Neighbor-Joinng method [54]. The robustness of the internal branches was also assessed with 1000 bootstrap replication [55]. The evolutionary distances were computed using Maximum Composite Likelihood method [56] and were calculated in the units of the number of base substitutions per site.

Identification of peptaibols production from T. lixii (IIIMB4) through intact cell mass spectrometry by MALDI TOF mass spectrophotometer

The endophytic fungus was grown on potato dextrose for a period of 15 days at $25 \pm 2{ }^{\circ} \mathrm{C}$ in an incubator (New Brunswicks, USA). One disc $(5 \mathrm{~mm})$ from 15 -day old fungal culture plate was used as inoculum. Post fifteen days, fungal growth of all five petri-plates was used for the extraction of secondary metabolites separately.

A few milligrams of fungal mycelia (1-5 mg) was scraped from agar petri plates and suspended in acetonitrile/methanol/water $(1,1,1)$. The suspension was homogenized thoroughly followed by centrifugation at $5000 \mathrm{~g}$ for $15 \mathrm{~min}$. Ten $\mu \mathrm{L}$ of this solution was mixed well with $10 \mu \mathrm{L}$ of matrix solution ( $\alpha$-cyano-4-hydroxy cinnamic acid $5 \mathrm{mg} / \mathrm{mL}$ in acetonitrile:water 70:30). It was homogenized well and mixed properly by vortexing for $5 \mathrm{~min}$ in an eppendorf tube and then centrifuged at $5000 \mathrm{rpm}$ for $5 \mathrm{~min} .1 \mu \mathrm{L}$ of this mixture was then directly spotted onto target wells of 96 or 364 well plate using premixed two layer volume technique and allowed to air dry prior to analysis. For metabolic profiling,
Matrix Assisted Laser Desorption/Ionisation-Time of Flight (MALDI-TOF) mass spectrometer was employed. MALDI-TOF mass spectra was obtained on Applied Biosystems 4800 MALDI TOF/TOF analyzer (AB Sciex, Foster city, USA), equipped with Nd:YAG $200 \mathrm{~Hz}$ laser. The extraction voltage was set at $20 \mathrm{kV}$. To avoid the saturation of detector by matrix ions, gated matrix suppression was applied. The instrument was operated in positive ion reflectron mode. Ions were extracted from 10 different regions of same sample spot. Ion extraction from each region was the result of the accumulation of at least 1000 laser shots having 10 subspectra or 100 shots per subspecta. Mass range was from $\mathrm{m} / z 500$ to 2500. Bin size was $0.5 \mathrm{~ns}$ and band width was set at 500 $\mathrm{MHz}$. The $\mathrm{S} / \mathrm{N}$ ratio was kept at 100 to reduce ions arising from matrix and their clusters, small peptides and other unknown contaminants. Mass accuracy was set at $\pm 0.05 \mathrm{Da}[57,58]$. Further, MS/MS studies using collision ion dissociation through MALDI-TOF/TOF mass spectrometer were carried out to confirm these peptides as peptaibols.

\section{Evaluation of different growth medium for optimal production of peptaibols}

Different growth media were used for optimal production of peptaibols using ICMS technique. The media were i) Potato Dextrose Agar (PDA) ii) malt extract agar iii) yeast extract malt extract agar iv) Sabouraud dextrose v) Oat meal agar, vi) Rose Bengal agar vii) Potato carrot agar viii) Corn meal agar ix) Synthetic medium [Glucose $5 \mathrm{~g}$; Potassium dihydrogen phosphate $0.8 \mathrm{~g}$; Potassium nitrate $0.72 \mathrm{~g}$; Calcium dihydrogen phosphate $0.2 \mathrm{~g}$; Magnesium sulphate $0.5 \mathrm{~g}$; Manganese sulphate $0.01 \mathrm{~g}$; Zinc sulphate $0.01 \mathrm{~g}$; Copper sulphate $0.005 \mathrm{~g}$; Ferrous sulphate 0.001 Agar $15 \mathrm{~g}$; Distilled $\mathrm{H}_{2} \mathrm{O} 1 \mathrm{~L}$ ] x) synthetic medium [Yeast extract $5 \mathrm{~g}$; Sucrose $30 \mathrm{~g}$; Di-potassium ortho-phosphate $2 \mathrm{~g}$; Magnesium sulphate $0.5 \mathrm{~g}$; Potassium chloride $0.5 \mathrm{~g}$; Zinc sulphate $0.01 \mathrm{~g}$; Copper sulphate $0.7 \mathrm{~g}$; Ferrous sulphate 0.01 Agar $15 \mathrm{~g}$; Distilled $\mathrm{H}_{2} \mathrm{O} 1 \mathrm{~L}$ ]. On these media, Growth characteristics vis a vis peptaibols production were evaluated. Extraction of fungal samples was carried out as described before.

\section{Isolation and characterization of a peptaibol}

For isolation of peptaibols, T. lixii (IIIM-B4) was grown on rose bengal agar (500 plates) for a period of 15 days at $25 \pm 2{ }^{\circ} \mathrm{C}$ in an incubator (New Brunswick, USA). One block $(0.5 \mathrm{~cm})$ from 10-day old fungal culture was used as inoculum. After fifteen days, fungal growth of all petri-plates was used for the extraction of peptaibols as mentioned before.

Isolation of the peptaibol from the extract was achieved by HPLC (Agilent) using a Waters Spherisorb DDS2 column, $5 \mu \mathrm{m}, 250 \times 10 \mathrm{~mm}$. The mobile phases 
were water acetonitrile with $0.1 \%$ formic acid. Flow rate was adjusted to $2 \mathrm{~mL} / \mathrm{min}$. Wavelengths used for detection were 214, 220 and $254 \mathrm{~nm}$. Method was \%B (acetonitrile with $0.1 \%$ formic acid) 60 to $95 \%$ in $5 \mathrm{~min}$, then in next $3 \mathrm{~min}$ to $80 \%$ and keeping it for another $5 \mathrm{~min}$ and then till 25 min dropping back to $60 \%$ which continued for another $3 \mathrm{~min}$. Further, it was sequenced through mass studied.

\section{Antimicrobial activity of isolated peptaibol}

Pathogens viz. Bacillus subtilis (MTCC No. 121), Staphylococcus aureus (MTCC No. 737), Salmonella typhimurium (MTCC No. 98), Pseudomonas aeruginosa (MTCC No. 424), Escherichia coli (MTCC No. 118), Klebsiella pneumoniae (MTCC No. 109), Candida albicans (MTCC No. 183) were procured from Microbial Type Culture Collection (MTCC), Chandigarh (India) and were grown on Muller Hinton agar while C. albicans was grown on Yeast extract peptone dextrose agar (YEPD). The antibacterial activity following the CLSI protocol was studied against the test organisms by microdilution assay [43, 47, 48]. Streptomycin and Amphotericin B were used as positive controls for bacterial pathogens (both Gram-positive and Gram-negative) and for C. albicans respectively. Bacterial strains were inoculated into Muller Hinton broth (Hi Media Biosciences) and incubated at $37^{\circ} \mathrm{C}$ while C. albicans was grown into YEPD medium (Hi Media, Biosciences) at $30^{\circ} \mathrm{C}$ with shaking $(200 \mathrm{rpm})$ for $16 \mathrm{~h}$. The cells were quantified according to Mc Farland standard turbidity (0.5 equivalent to $1.5 \times 10^{8}$ colony forming units $(\mathrm{CFU} / \mathrm{mL})$ and finally diluted to $1.5 \times 10^{5} \mathrm{CFU} / \mathrm{mL}$ for all pathogens. Different dilutions $(1-100 \mu \mathrm{g} / \mathrm{mL}, 0.078-10 \mu \mathrm{g} / \mathrm{mL})$ were prepared from the stock solutions of fungal compound $(10 \mathrm{mg} / \mathrm{mL}$ in DMSO) and antibiotic ( $1 \mathrm{mg} / \mathrm{mL}$ in water). $150 \mu \mathrm{L}$ of each concentration of fungal compound and antibiotics were mixed with $50 \mu \mathrm{L}$ of media containing $4 \times 10^{4}$ bacterial cells (diluted from stock of $1.5 \times 10^{8} \mathrm{CFU} / \mathrm{mL}$ ). Appropriate negative (DMSO-0.5\%) and blank controls (virgin media) were used. 96-well plate was incubated overnight at $37^{\circ} \mathrm{C}$ in an incubator shaker with $150 \mathrm{rpm}$.

Activities were expressed in terms of minimum inhibitory concentration (MIC)/ minimum bactericidal concentration $(\mathrm{MBC})$. The lowest concentration with no visible growth after $18-24 \mathrm{~h}$ was considered as minimum inhibitory concentration (MIC) [59]. $50 \mu \mathrm{L}$ mix of the well showing no growth and two preceding wells were plated on MHA and incubated overnight. to find out their static/cidal effect. The lowest concentration of extract which didn't contain any bacterial growth upon spotting $50 \mu \mathrm{l}$ of mix on MHA plates after $24 \mathrm{~h}$ incubation at $37^{\circ} \mathrm{C}$ was referred as the minimum bactericidal concentration (MBC). The assay was replicated thrice.

\section{Results \\ Morphological and molecular characterization of Trichoderma lixii (IIIM-B4)}

Endophytic fungi IIIM-B4 was isolated from healthy and symptomless leaves of $B$. monnieri to isolate the bioactive molecule. Endophyte was identified by its characteristic colony morphology and microscopic features (Fig. 1). T. lixii (IIIM-B4) grew slowly on PDA medium with white cottony hyphae. Mycelium appeared first smooth, watery white in color, sparse, until floccose aerial mycelium produced. Fifteen-twenty days post incubation; greenish conidia were appeared on the culture plate. In microscopic view, pyramidal conidiophores and effuse conidiation were observed. Ampulliform to flask-shaped phialides were found to have globose or subglobose conidia. In old cultures, terminal or intercalary chlamydospore were also visualized. Growth characteristics of Trichoderma lixii B4 on different medium were mentioned in Additional file 1: Table S1 and shown in Additional file 1: Figure S1.

Further their molecular identification was carried out by ITS based rDNA sequence analysis. Details of the closest sequence homologs of fungal endophyte, their isolation source and their GenBank accession numbers are given in Table 1. Furthermore, ITS sequence data showed that the endophyte is a strain of the Trichoderma lixii (Fig. 2). The ITS1 5.8S ITS2 region of ribosomal gene of IIIM-B4 showed a maximum homology of 99\% with different Trichoderma harzianum species complex. The highest score was displayed for Hypocrea lixii strain FJ462763 followed by $H$. nigricans strain NBRC31285, T. lixii strain CBS 110080, T. afroharzianum strain CBS124620 and T. guizhouense BPI:GJS 08135 respectively. To characterize T. lixii (IIIM-B4), a phylogenetic tree was constructed which contained two clusters. T. lixii (IIIM-B4) was laid down in Cluster I with Hypocrea lixii, H. nigricans, T. lixii, T. afroharzianum, T. guizhouense, T. harzianum, while cluster II contained $T$. virens, $T$. atroviride, T. erinaceus, T. asperellum and T. viride.

ITS Sequence of IIIM-B4 was also analyzed through TrichOKEY tool. Reliability of BLAST results was found high. Analysis revealed that it belonged to Genus Trichoderma, Section I Lixii - Catoptron Clade, Species Hypocrea lixii/T. harzianum. Results were in agreement with the results obtained from GenBank database.

Identification of peptaibols production from T. lixii (IIIM-B4) T. lixii (IIIM-B4) extract was analyzed through ICMS and was found to be the producer of peptaibols. Illustrious peptaibols spectra of B4 showed characteristic metabolite fingerprints of 11 residue peptaibols (Group A) having mass of $m / z 1169,1185,1198,1199,1213,1215$, 1357, 14 residue peptaibols (Group B) having masses as 

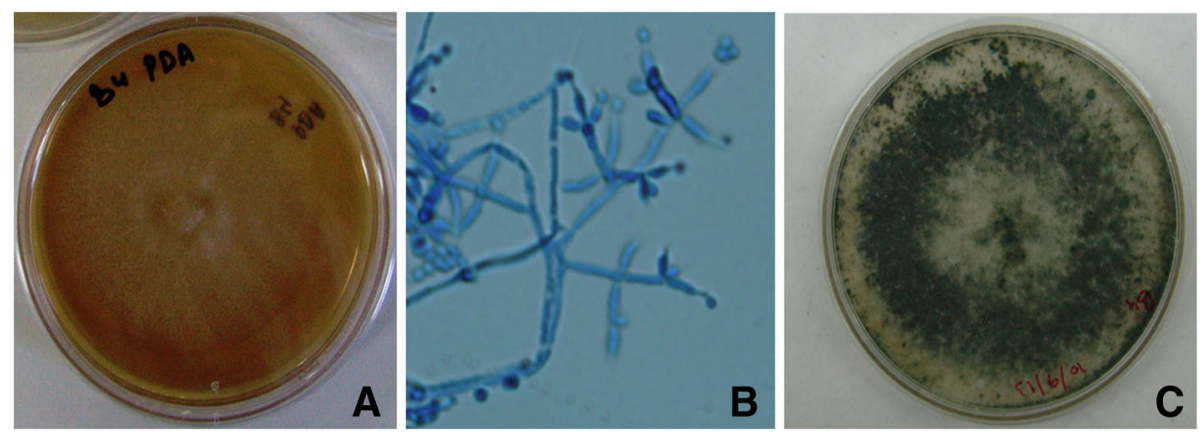

Fig. 1 Morphological and microscopical view of Trichoderma lixii (IIIM-B4) endophytic fungi associated with B. monnieri at 400X magnification a) Growth of IIIM-B4 on PDA for 15 days b) microscopically view of IIIM-B4 stained with lacto phenol cotton blue c) Growth of IIIM-B4 on Rose Bengal medium for 15 days

1466, 1467, 1482, 1484, 1496 and 17 residue peptaibols (Group C) showing masses as 1699, 1756, 1768, 1770 indicating three groups of peptaibols falling in respective medium, medium and long chain length of peptaibols (Fig. 3). MS/MS studies using collision ion dissociation through MALDI-TOF/TOF mass spectrometer were used to characterize these peptides. According to MS/ MS spectra, presence of non standard amino acids like $\alpha$-aminoisobutyrate, Aib (U), clearly confirms the identity of peptaibols (Fig. 4). Medium chain peptides having masses $m / z 1169,1185,1198,1199,1213,1215,1357$ and 1466, 1467, 1482, 1484, 1496 belonged to subfamily $\mathrm{SF} 4$, where as long chain peptides having mass $\mathrm{m} / \mathrm{z}$ $1699,1756,1768,1770$ belonged to subfamily SF1, under physiological pH 7.0.

Effect of different solid medium on peptaibols production Peptaibols production was studied through media optimization using ICMS technique (Additional file 1: Figure S2 a'-j). Summation of media optimization studies was shown in Fig. 5, which indicated best quantitative formation of Group A short chain peptaibiotics, named as Tribacopins I-VII in solid media particularly in rose bengal medium upto five fold.

\section{Isolation and characterization of a peptaibol}

Using the mentioned HPLC program, separation of 11 residue medium chain peptaibols (Fraction A named as Tribacopin AI - AVII) having mass as 1169, 1183, 1184, 1185, 1197, 1198, 1199, 1213 was achieved from long chain peptaibols (Fraction $\mathrm{C}$ named as Tribacopin CI-CIII) having mass as 1727, 1729 and 1742 as shown in Additional file 1: Figure S3. Fraction A was further purified and Tribacopin AV having mass as $\mathrm{m} / \mathrm{z}$ 1185 was isolated as shown in Additional file 1: Figure S4. Further, it was sequenced through mass studied. It was found to have a novel sequence (Ac-Gly-Leu-Leu-Leu-Ala-Leu-Pro-Leu-Aib-Val-Gln-OH) as shown in Fig. 6 and Additional file 1: Figure S5.

\section{Antimicrobial activity of Tribacopin AV}

Tribacopin AV was tested for antimicrobial activity and was found to have antifungal activity against $C$. albicans $(25 \mu \mathrm{g} / \mathrm{mL}$ MIC) but not active against bacterial pathogens (Additional file 1: Table S2).

Table 1 Comparison of the 16 s rRNA gene sequence of IIIM-B4 among isolates of Streptomyces

\begin{tabular}{|c|c|c|c|c|}
\hline Species & Strain & Similarity (\%) & Total score & GenBank accession number \\
\hline Hypocrea lixii & FJ462763 & 99 & 1109 & FJ462763 \\
\hline Hypocrea nigricans & NBRC31285 & 99 & 1096 & JN943368 \\
\hline Trichoderma lixii & CBS 110080 & 99 & 1090 & NR_131264 \\
\hline T. afroharzianum & CBS124620 & 99 & 1066 & NR137304 \\
\hline T. guizhouense & BPI:GJS 08135 & 99 & 1040 & KP115286 \\
\hline T. harzianum & ATCC58674 & 99 & 959 & AF057584 \\
\hline T. virens & ATCC9645 & 97 & 998 & KU729029 \\
\hline T. atroviride & ATCC20476 & 90 & 739 & $J Q 745258$ \\
\hline T. erinaceus & ATCCMYA4844 & 90 & 728 & KC171340 \\
\hline T. asperellum & CBS433.97 & 89 & 645 & NR130668 \\
\hline T. viride & ATCC28038 & 88 & 625 & AY380909 \\
\hline
\end{tabular}




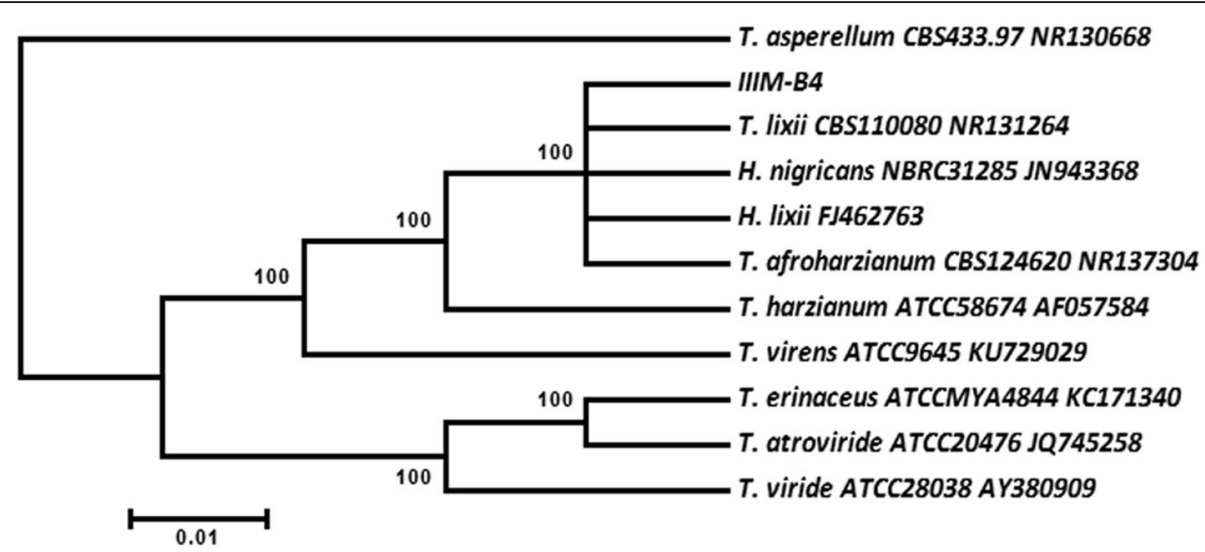

Fig. 2 Phylogenetic Tree based on ITS-5.8S rDNA sequence of Trichoderma lixii (IIIM-B4) endophytic fungi associated with B. monnieri showing the relative position of its close relatives

\section{Discussion}

Endophytes are ubiquitous in nature. Diverse endophytes have been reported. Endophytes from unique sources are thought to be the producer of unique metabolites. Recent studies have reported isolation of $T$. lixii (IIIM-B4) as endophytes from $B$. monnieri (L.), an ethano-medicinal plant $[43,44]$. Phylogenetic characterization based on ITS rDNA sequence suggested that T. lixii (IIIM-B4) is a unique strain and showed similarity with Hypocrea lixii, $H$. nigricans, T. lixii, T. afroharzianum, T. guizhouense, $T$. harzianum but placed separately in phylogenetic tree. Hypocrea lixii/nigricans is a teleomorphic stage of $T$. harzianum, a multispecies complex containing more than thirteen species. Many species including T. lixii, T. afroharzianum, T. guizhouense, T. harzianum belong to $T$. harzianum species complex [60]. Most of the Trichoderma spp. including the endophytic ones are peptaibol producers [27]. These peptaibols exhibit a variety of indispensable bioactivities [61]. Metabolite profiling of T. lixii (IIIM-B4) using ICMS approach showed intense signals of
11, 14 and 18 residue peptaibols belonging to subfamily 1 and 4. Characterization was done by MS/MS studies using collision ion dissociation through MALDI-TOF/TOF mass spectrometer. According to MS/MS spectra, characteristic feature of presence of non standard amino acids like $\alpha$-aminoisobutyrate, Aib (U), clearly indicated the presence of peptaibols. Similar to present study, Mukherjee et al. [62] also reported 11, 14 and 18 residue peptaibols from $T$. virens, a rhizospheric strain. In contrast to present study, Maddau et al. [27] reported 20 residue peptaibols from an endophyte $T$. citrinoviridae isolated from Cork Oak. Szekeres et al. [31] reported that Trichoderma/Hypocrea genus produces the peptaibols of subfamilies 1, 4, 5 and 9 .

Optimization is an important aspect for production of desirable metabolite from a microbial strain. Less production of desired metabolites has always been a bottleneck in carrying out purification steps for further studies. While investigating the effect of solid medium on production of peptaibols from T. lixii (IIIM-B4), it

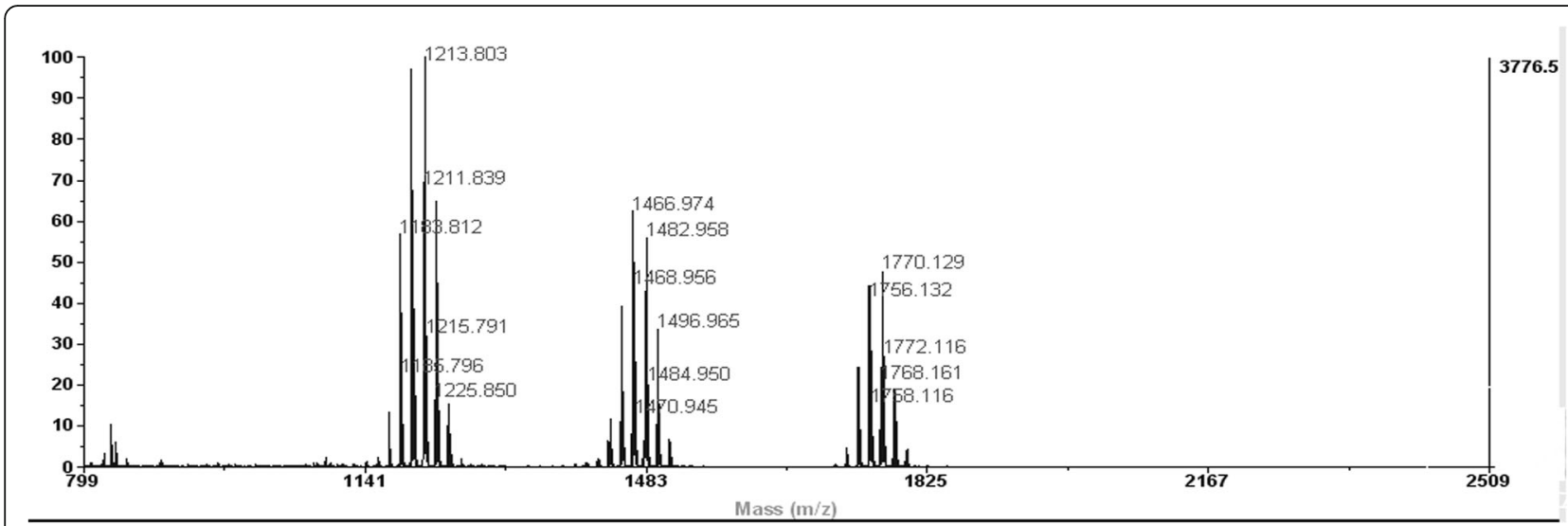

Fig. 3 Mass spectral profile of Trichoderma lixii (IIIM-B4) obtained through Intact Cell Mass Spectrometry by MALDI TOF mass analyzer indicating three groups of peptaibiotics medium and long chain length 


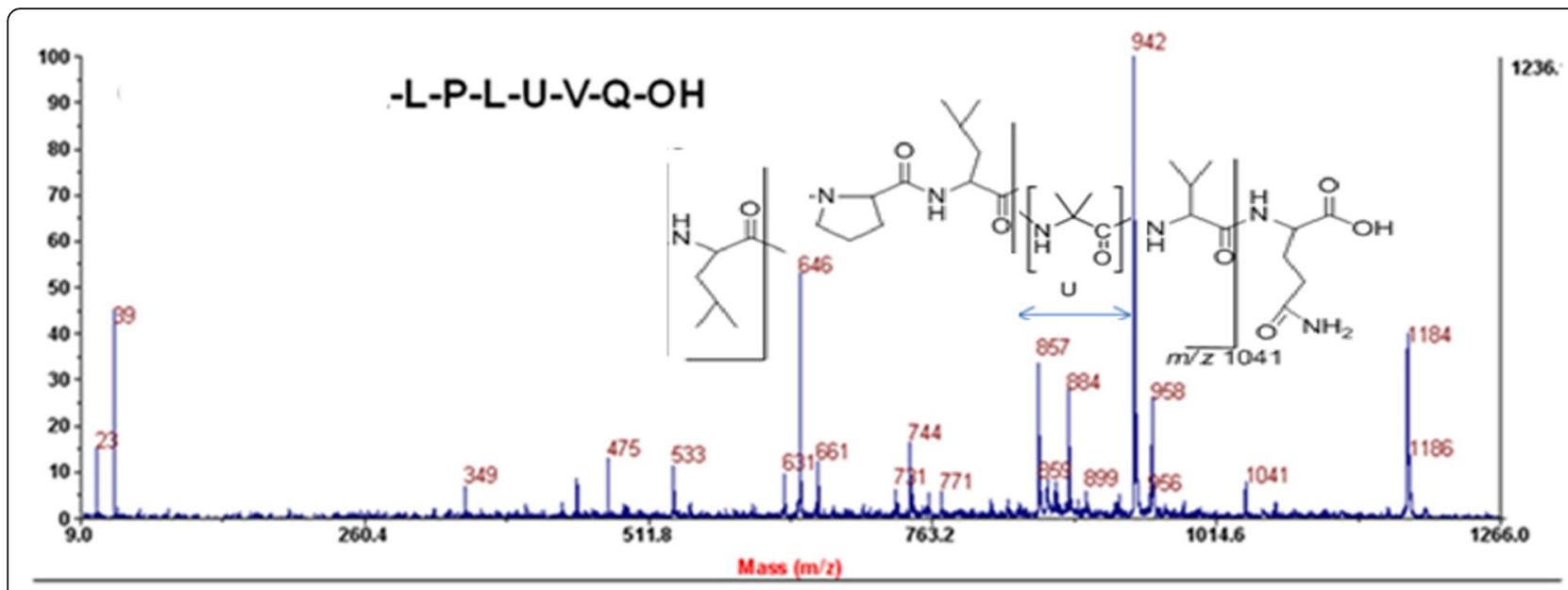

Fig. 4 MS/MS spectra showing fragmentation of m/z 1185 production by Trichoderma lixii (IIIM-B4) for confirming peptaibols

was astonishing to observe that production of all the peptaibols were not same on different medium. It was found that one or the other desired group of peptaibols was getting adversely affected. Thus, one culture condition does not seem to be advantageous for maximum production of all peptaibols; moreover, it hinders identification of metabolites and their efficient purification. Thus, optimization experiments are important for increasing the yield of desirable secondary metabolites by reducing complexities of natural mixtures to a great extent by favoring the production of one group of metabolite in its respective optimized conditions and giving an edge in process of purification [63]. Bode et al. [64] also reported that small changes in culture conditions affects pronouncedly the production of different metabolites. It has been observed that subsequent storage and sub-culturing under the optimized conditions, further enhances their production.

\section{Tribacopin AV characterization and its bioactivity}

Using the HPLC, Tribacopin AV was isolated having mass $m / z$ as 1185 . Its sequence was found novel. The new sequence showed connexion with very unique positioning of 2-aminoisobutyric acid (Aib), a hallmark of fungal peptaibols at 9th position, observed across all Trilongins AO, AI, AII a-e, AIII a-d, AIV a-c, Trichorovins

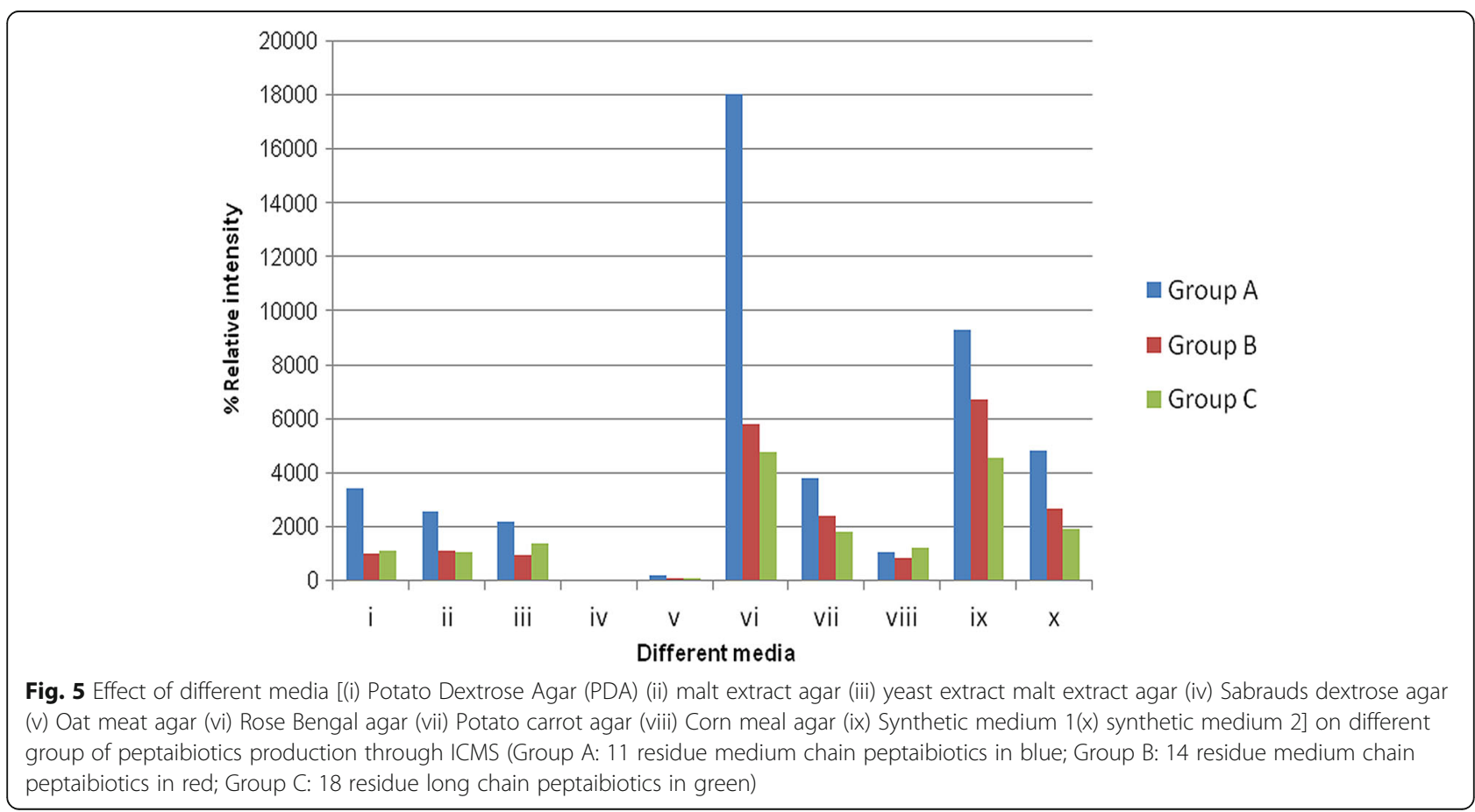




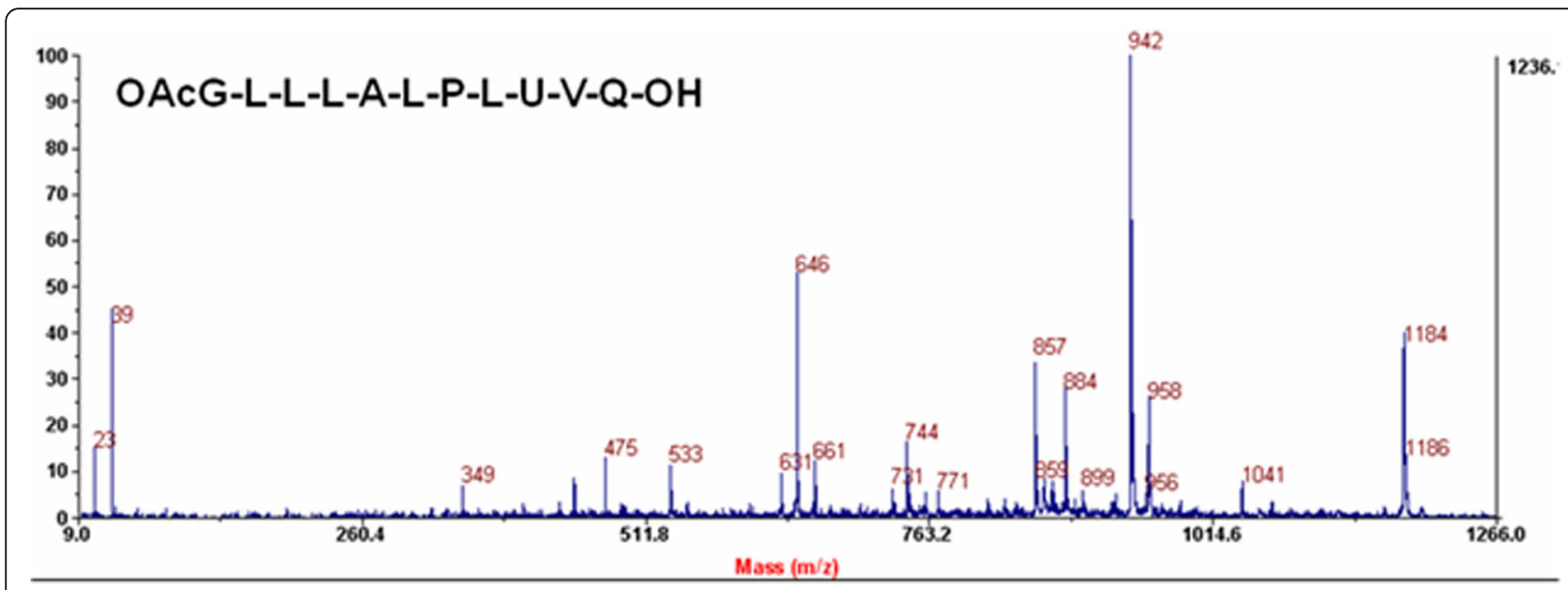

Fig. 6 MS/MS spectra showing Sequence of Tribacopin AV

I, IV, XIII, XIV, Hypomurocin A-I, Trichobrachins III, VTII, IXa and Trichozin IV. Stimulatingly it was also pragmatic that position of leucine at 3rd and 4th is also concurrent in new sequence of Tribacopin $\mathrm{V}$ which is seen in Trilongins AO, AI and in AII a-c Trichobrachins III, Trichorovins VTII, IXa and Hypomurocin A-3. Leu at position 3rd along with Aib at position 9th is seen in Trilongins AII d and in Trilongins A III a-b, Trichobrachins III, Trichorovins XIII, XIV, Hypomurocins A-5, A-5a and Trichorozin IV. Leucine at position 4th along with Aib at position 9th is seen in Trilongins A II e, Trilongins A III c-d, Trichobrachins III, Trichorovins XIII, XIV, Hypomurocins A-5, A-5a and Trichorozin IV [25, 62, 65]. The sequence isolated from Trichoderma lixii (IIIM-B4) showed remarkably the unique difference from across all Trilongins, Trichorovins, Trichobrachins, Trichorozins and Hypomurocins that position 5th and 6th is replaced by Alanine-Leucine instead of $\alpha, \alpha$-di alkyl amino isobutyric acid-Proline [66]. The unique 10th position of Proline observed across all Trilongins, Trichorovins, Trichobrachins, Trichorozins and Hypomurocins is replaced by Valine in Tribacopin AV (Additional file 1: Table S3). This is the first report of Tribacopin AV with novel sequence produced from $T$. lixii (IIIM-B4) isolated from medicinal plant B. monnieri L.

Tribacopin AV was analyzed against human bacterial and fungal pathogens. It was found to have antifungal activity against $C$. albicans $(25 \mu \mathrm{g} / \mathrm{mL} \mathrm{MIC}$, static effect) only. Similarly Heptaibin, an antifungal peptaibol antibiotic (against C. albicans with MIC $32 \mu \mathrm{g} / \mathrm{mL}$ ) has been reported from Emericellopsis lixii BAUA8289 [67].

\section{Conclusions}

Thus, present study describes a strain of Trichoderma lixii (IIIM-B4) which was isolated as an endophyte from Bacopa monnieri L. and showed the production of antifungal peptaibol. IIIM-B4, the only reported Trichoderma, as an endophyte of Bacopa monnieri has not yet been explored for neurological disorders, but recently a study suggested that a new cyclopentenone isolated from Trichoderma sp. with free radical scavenging properties, might be effective in Alzheimer's disease (AD) models (Harrison 2012). Hence it can also be explored for neurological disorders.

\section{Additional file}

Additional file 1: Table S1. Mycelia growth, Colony characters and sporulation pattern of B4 culture plate on different medium. Table S2. Antimicrobial activities of extract of Trichoderma lixii (IIIM-B4). Microorganisms used were Bacillus subtilis, Pseudomonas aeruginosa, Salmonella typhimurium, Escherichia coli, Klebsiella pneumonia, Staphylococcus aureus, Candida albicans. The lowest concentration at which there was no visible growth after $16 \mathrm{~h}$ was considered as minimum inhibitory concentration (MIC). Table S3. Comparative summation of novel Tribacopin AV and known sequences of 11 residue peptaibols produced by Trichoderma lixii. Figure S1. Mycelia growth, Colony characters and sporulation pattern of Trichoderma lixii (IIIM-B4) endophytic fungi on different medium (i) Potato Dextrose Agar (PDA) (ii) malt extract agar (iii) yeast extract malt extract agar (iv) Sabourauds dextrose agar (v) Oat meat agar (vi) Rose Bengal agar (vii) Potato carrot agar (viii) Corn meal agar (ix) Synthetic medium 1(x) synthetic medium 2. Figure S2. Mass studies depicting the peptaibols production from Trichoderma lixii (IIIM-B4) in different media. Figure S2a) Potato Dextrose Broth Figure S2a') Potato Dextrose Agar Figure S2b) Malt extract agar Figure S2c) Yeast extract malt agar MEA Figure S2d) Sabourauds dextrose agar Figure S2e) Oat meat agar Figure S2f) Rose Bengal agar Figure S2g) Potato carrot agar Figure S2 h) Corn meal agar Figure S2i) Synthetic medium 1 Figure S2j) Synthetic medium 2. Figure S3. Separation of Group A peptaibols from Group C from extract of Trichoderma lixii through HPLC. Figure S4. Mass spectra of peptaibol Tribacopin AV having mass 1185. Figure S5. Sequence of Tribacopin AV based on MS/MS studies. (DOC $7700 \mathrm{~kb}$ )

Abbreviations

ITS: Internal transcribed spacer; MIC: Minimum inhibitory concentration 


\section{Acknowledgements}

This article bears the Institutional Publication No. IIIM/2186/2019. The authors are thankful to the Director, Indian Institute of Integrative Medicine, Jammu. We acknowledge the Council of Scientific and Industrial Research (CSIR) for proving the platform for research.

\section{Availability of data and material}

Most of the data generated or analysed during this study are included in this published article and its Additional file.

The ITS sequences from endophytic isolates are available via the following links: http://www.ncbi.nlm.nih.gov/nuccore/KF683907.

Rest of raw datasets during the current study can be available from the corresponding author on reasonable request.

\section{Funding}

The research conducted in this manuscript was supported by DBT sponsored project GAP1182 (BT/PR4669/PBD/17/784/2012), and Council of Scientific and Industrial Research (CSIR) Net-Working (BSC0117) and MLP4010 project, Government of India. Currently there is no funding.

\section{Author's contributions}

RV designed the study and reviewed the research paper. MK carried out the isolation and molecular characterization of endophytes, fermentation and the antimicrobial experiments. DS carried out the extraction and Mass studies. All authors read and approved the final manuscript.

\section{Ethics approval and consent to participate}

Not applicable.

\section{Consent for publication}

Not applicable.

\section{Competing interests}

The authors declare that they have no competing interests.

\section{Publisher's Note}

Springer Nature remains neutral with regard to jurisdictional claims in published maps and institutional affiliations.

\section{Author details}

'Microbial Biotechnology Division, Indian Institute of Integrative Medicine, Canal Road, Jammu 180001, India. ${ }^{2}$ Quality Control and Quality Assurance Division, Indian Institute of Integrative Medicine, Canal Road, Jammu 180001, India. ${ }^{3}$ Department of Chemistry, University of Jammu, Jammu 180001, India. ${ }^{4}$ Medicinal Chemistry Division, Indian Institute of Integrative Medicine, Jammu, India.

Received: 28 March 2018 Accepted: 7 May 2019

Published online: 16 May 2019

\section{References}

1. Newman DJ, Cragg GM. Natural products as sources of new drugs over the last 25 years. J Nat Prod. 2007;70:461-77.

2. Staniek A, Woerdenbag HJ, Kayser O. Endophytes: exploiting biodiversity for the improvement of natural product-based drug discovery. J Plant Interact. 2008:3:75-93.

3. Kaul S, Gupta S, Ahmed M, Dhar MK. Endophytic fungi from medicinal plants: a treasure hunt for bioactive metabolites. Phytochem Rev. 2012;11:487-505.

4. Koehn FE, Carter GT. The evolving role of natural products in drug discovery. Nature Rev Drug Discov. 2005:4:206-20.

5. Cragg GM, Grothaus PG, Newman DJ. Impact of natural products on developing new cancer agents. Chem Rev. 2009;109:3012-43.

6. Jain SK. Ethnobotany and research in medicinal plants in India. CIBA Found Symp. 1994;185:153-64.

7. Russo A, Borrelli F. B. monnieri, a reputed nootropic plant: an overview. Phytomedicine. 2005;12:305-17

8. Jain P, Kulshreshtha DK. Bacoside A1, a minor saponin from B. monnieri. Phytochemistry. 1993;33:449-51.

9. Kapoor LD. CRC Handbook of Ayurvedic Medicinal Plants. Poca Raton: FL CRC Press; 1990
10. Jain P, Khanna NK, Trehan N, Pendse VK, Godhwani JL. Antiinflammatory effects of an Ayurvedic preparation, Brahmi Rasayan, in rodents. Ind J Exp Biol. 1994;32:633-6.

11. Sumathy T, Subramanian S, Govindasamy S, Balakrishna K, Veluchamy G. Protective role of $B$. monnieri on morphine induced hepatotoxicity in rats. Phtotherapy Res. 2001;15:643-5.

12. Sairam K, Dorababu M, Goel RK, Bhattacharya SK. Antidepressant activity of standardized extract of $B$. monnieri in experimental models of depression in rats. Phytomedicine. 2002;9:207-11.

13. Woo SL, Ruocco M, Vinalle F, et al. Trichoderma- based products and their widespred use in agriculture. The open Mycology Journal. 2014;8:71-126.

14. Harman GE. Myths and dogmas of biocontrol: changes in perceptions derived from research on T. harzianum T-22. Plant Dis. 2000:84:377-93.

15. Howell CR. Mechanisms employed by Trichoderma species in the biological control of plant diseases: the history and evolution of current concepts. Plant Dis. 2003;87:4-10.

16. Harman GE, Howell CR, Viterbo A, Chet I, Lorito M. Trichoderma spp. - opportunistic, avirulent plant symbionts. Nat Rev Microbiol. 2004:2:43-56

17. Marra R, Ambrosino P, Carbone V, Vinale F, Woo SL, Ruocco M, Ciliento R, Lanzuise S, Ferraioli S, Soriente I, et al. Study of the three-way interaction between $T$. atroviride, plant and fungal pathogens by using a proteomic approach. Curr Genet. 2006:50:307-21.

18. Vinale F, Sivasithamparam K, Ghisalberti EL, Marra R, Woo SL, Lorito M. Trichoderma-plant-pathogen interactions. Soil Biol Biochem. 2008;40:1-10.

19. Reino JL, Guerrero RF, Hernández-Galán R, Collado IG. Secondary metabolites from species of the biocontrol agent Trichoderma. Phytochem Rev. 2008;7:89-123.

20. Grondona I, Mr H, Tejada M, Md G, Pf M, Pd B, Monte E, Garcíaacha I. Physiological and biochemical characterization of T. harzianum, a biological control agent against soilborne fungal plant pathogens. Appl Environ Microbiol. 1997:63:3189-98.

21. Harman GE. Overview of mechanisms and uses of Trichoderma spp. Phytopathol. 2006:96:190-4.

22. Schuster A, Schmoll M. Biology and biotechnology of Trichoderma. App Microbiol Biotechnol. 2010;87:787-99.

23. Vinale F, Sivasithamparam K, Ghisalberti EL, Ruocco M, Wood S, Lorito M Trichoderma secondary metabolites that affect plant metabolism. Nat Prod Commun. 2012;7:1545-50

24. Daniel JF, De S, Filho ER. Peptaibols of Trichoderma. Nat Prod Rep. 2007;24:1128-41.

25. Rohrich $\mathrm{CR}$, Jaklitsch WM, Voglmayr H, Iversen A, Vilcinskas A, Nielsen KF, Thrane U, von Döhren H, Brückner H, Degenkolb T. Front line defenders of the ecological niche! Screening the structural diversity of peptaibiotics from saprotrophic and fungicolous Trichoderma/Hypocrea species. Fungal Divers. 2014;69:117-46.

26. Berg A, Grigoriev PA, Degenkolb T, Neuhof T, Härtl A, Schlegel B, Grafe U. Isolation, structure elucidation and biological activities of trichofumins a, B C and D, new 11 and 13mer peptaibols from Trichoderma sp. HKI 0276. J Peptide Sci. 2003;9:810-6.

27. Maddau L, Cabras A, Franceschini A, Linaldeddu BT, Crobu S, Roggio T, Pagnozzi D. Occurrence and characterization of peptaibols from $T$. citrinoviride, an endophytic fungus of cork oak, using electrospray ionization quadrupole time-of-flight mass spectrometry. Microbiology. 2009:165:3371-881.

28. Singh D, Sharma JP, Jaglan S, Dar AH, Khajuria A, Singh VP, Vishwakarma RA Brachiatin d and process for production thereof; 2014. p. WO2015029069 A1.

29. Yun BS, Yoo ID, Kim YH, Kim YS, Lee SJ, Kim KS, Yeo WH. Peptaivirins a and $B$, two new antiviral peptaibols against TMV infection. Tetrahedron Lett. 2000:41:1429-31.

30. Leclerc G, Goulard C, Prigent Y, Bodo B, Wróblewski H, Rebuffat S Sequences and Antimycoplasmic properties of Longibrachins LGB II and LGB III, two novel 20-residue Peptaibols from Trichoderma longibrachiatum. J Nat Prod. 2001:64:164-70.

31. Szekeres A, Leitgeb B, Kredics L, Antal Z, Hatvani L, Manczinger L, Vágvolgyi C. Peptaibols and related peptaibiotics of Trichoderma. Acta Microbiol Immunol Hung. 2005;52:137-68.

32. Degenkolb T, Grafenhan T, Nirenberg HI, Gams W, Brückner HT brevicompactum complex: rich source of novel and recurrent plantprotective polypeptide antibiotics (peptaibiotics). J Agric Food Chem. 2006;54:7047-61. 
33. Viterbo ADA, Wiest ARIC, Brotman Y, Chet ILAN, Kenerley C. The 18mer peptaibols from T. virens elicit plant defence responses. Mol Plant Pathol. 2007;8:737-46

34. Iwatsuki M, Kinoshita Y, Niitsuma M, Hashida J, Mori M, Ishiyama A, Namatame M, Nishihara-Tsukashima A, Nonaka K, Masuma R, Otoguro K. Antitrypanosomal peptaibiotics, trichosporins B-VIla and B-VIllb, produced by T. polysporum FKI-4452. J Antibiot. 2010;63:331-3.

35. Schulz B, Boyle C, Draeger S, Römmert AK, Krohn K. Endophytic fungi: a source of novel biologically active secondary metabolites. Mycol Res. 2002;106:996-1004.

36. Brotman Y, Kapuganti JG, Viterbo A. Trichoderma. Curr Biol. 2010;20:R390-1.

37. Neuhof T, Dieckmann R, Druzhinina IS, Kubicek CP, von Döhren H. Intact-cell MALDI-TOF mass spectrometry analysis of peptaibol formation by the genus Trichoderma/Hypocrea: can molecular phylogeny of species predict peptaibol structures? Microbiology. 2007;153:3417-37.

38. Neuhof T, Berg A, Besl H, Schwecke T, Dieckmann R, von Dohren H. Peptaibol production by Sepedonium strains parasitizing boletales. Chem Biodivers. 2007:4:1103-15.

39. Ilina EN. Direct matrix-assisted laser desorption-ionisation (MALDI) massspectrometry bacteria profiling for identifying and characterizing pathogens. Acta Nature. 2009:1:115-20.

40. Helmel M, Marchetti-Deschmann M, Raus M, Posch AE, Herwig C, Sebela M, Allmaier $\mathrm{G}$. Intact cell mass spectrometry as a progress tracking tool for batch and fed-batch fermentation processes. Anal Biochem. 2015;470:25-33.

41. Sharma R, Singh VP, Singh D, Yusuf F, Kumar A, Vishwakarma RA, Chaubey A. Optimization of nonribosomal peptides production by a psychrotrophic fungus: T. velutinum ACR-P1. Appl Microbiol Biotechnol. 2016;100:9091-102.

42. Strobel G, Daisy B. Bioprospecting for microbial endophytes and their natural products. Microbiol Mol Biol Rev. 2003;67:491-502.

43. Katoch M, Salgotra A, Singh G. Endophytic fungi found in association with B. monnieri as resourceful producers of industrial enzymes and antimicrobial bioactive natural products. Braz Arch Biol Techn. 2014a;57:714-22.

44. Katoch M, Singh G, Sharma S, Gupta N, Sangwan PL, Saxena AK. Cytotoxic and antimicrobial activities of endophytic fungi isolated from B. monnieri (L) Pennell (Scrophulariaceae). BMC Complem Altern M. 2014b;14:52.

45. Raeder $U$, Broda P. Rapid preparation of DNA from filamentous fungi. Lett Appl Microbiol. 1985;1:17-20.

46. Katoch M, Paul A, Singh G, Sridhar SN. Fungal endophytes associated with Viola odorata Linn. As bioresource for pancreatic lipase inhibitors. BMC Complement Altern Med. 2017;17:385

47. Singh G, Katoch A, Razak M, Kitchlu S, Goswami A, Katoch M. Bioactive and biocontrol potential of endophytic fungi associated with Brugmansia aurea Lagerh. FEMS Microbiol Lett. 2017;364:fnx194.

48. Katoch $M$, Singh $A$, Singh $G$, et al. Phylogeny, antimicrobial, antioxidant and enzyme-producing potential of fungal endophytes found in V. odorata. Ann Microbiol. 2017:67:529-40.

49. White TJ, Bruns T, Lee SJWT, Taylor JW. Amplification and direct sequencing of fungal ribosomal RNA genes for phylogenetics. In: Innis M, Gelfand D, Sninsky J, White T, editors. PCR protocols. San Diego: Academic press; 1990. p. 315-22.

50. Altschul SF, Madden TL, Schaffer AA, Zhang J, Zhang Z, Miller W, Lipman DJ. Gapped BLAST and PSI-BLAST: a new generation of protein database search programs. Nucleic Acids Res. 1997;25:3389-402.

51. Druzhinina IS, Kopchinskiy AG, Komo oligonucleotide barcode for species identification in Trichoderma and Hypocrea. Fungal Genet Biol. 2005;42:813-28.

52. Edgar RC. MUSCLE: multiple sequence alignment with high accuracy and high throughput. Nucleic Acid Res. 2004;32:1792-7.

53. Tamura K, Dudley J, Nei M, Kumar S. MEGA4: molecular evolutionary genetics analysis (MEGA) software version 4.0. Mol Bio Evol. 2007;24:1596-9.

54. Saitou N, Nei M. The neighbor-joining method: a new method for reconstructing phylogenetic trees. Mol Biol Evol. 1987;4:406-25.

55. Felsenstein J. Confidence limits on phylogenies: an approach using the bootstrap. Evolution. 1985;39:783-91.

56. Tamura K, Nei M, Kumar S. Prospects for inferring very large phylogenies by using the neighbor-joining method. Proc Natl Acad Sci U S A. 2004;101:11030-5.

57. Rebuffat S, Prigent Y, Auvin-guette C, Bodo B. Tricholongins BI and BII, 19residue peptaibols from T. longibrachiatum. Eur J Biochem. 1991;201:661-74.

58. Mitova MI, Murphy AC, Lang G, Blunt JW, Cole AL, Ellis G, Munro MH. Evolving trends in the dereplication of natural product extracts. 2. The isolation of chrysaibol, an antibiotic peptaibol from a New Zealand sample of the mycoparasitic fungus Sepedonium chrysospermum. J Nat Prod. 2008;71:1600-3.

59. Mourey A, Canillac N. Anti-listeria monocytogenes activity of essential oils components of conifers. Food Control. 2002;13:289-92.

60. Chaverri P, Rocha FB, Jaklitsch W, Gazis R, Degenkolb T, Samuels GJ. Systematics of the $T$. harzianum species complex and the re-identification of commercial biocontrol strains. Mycologia. 2015;107:558-90.

61. Chugh JK, Wallace BA. Peptaibols: models for ion channels. Biochem Soc Trans. 2001;29:565-70

62. Mukherjee PK, Wiest A, Ruiz N, Keightley A, Moran-Diez ME, McCluskey K, Pouchus YF, Kenerley CM. Two classes of new peptaibols are synthesized by a single non-ribosomal peptide synthetase of T. virens. J Biol Chem. 2011;286:4544-54

63. Paranagama PA, Wijeratne EK, Gunatilaka AL. Uncovering biosynthetic potential of plant-associated fungi: effect of culture conditions on metabolite production by Paraphaeosphaeria quadriseptata and Chaetomium chiversii (1). J Nat Prod. 2007;70:1939-45.

64. Bode HB, Bethe B, Hofs R, Zeeck A. Big effects from small changes: possible ways to explore nature's chemical diversity. ChemBioChem. 2002;3:619-27.

65. Mikkola R, Andersson MA, Kredics L, Grigoriev PA, Sundell N, SalkinojaSalonen MS. 20-residue and 11-residue peptaibols from the fungus $T$. longibacterium are synergistic in forming $\mathrm{Na}^{+} / \mathrm{K}^{+}$permeable channels and adverse action towards mammalian cells. FEBS J. 2012;279:4172-90.

66. Ruiz N, Weilgosz CG, Grovel O, Petit KE, Benkada M, Mohamed DPTR, Bissett J. Verite P, Barnathan G, Pouchus YF. New trichobrachins, 11 residue peptaibols from a marine strain of $T$. longibrachiatum. Peptides. 2007:28:1351-8

67. Ishiyama D, Satou T, Senda H, Fujimaki T, Honda R, Kanazawa S. Heptaibin, a novel antifungal peptaibol antibiotic from Emericellopsis sp. BAUA8289. The J Antibiotics. 2000:53:728-32.
Ready to submit your research? Choose BMC and benefit from:

- fast, convenient online submission

- thorough peer review by experienced researchers in your field

- rapid publication on acceptance

- support for research data, including large and complex data types

- gold Open Access which fosters wider collaboration and increased citations

- maximum visibility for your research: over $100 \mathrm{M}$ website views per year

At BMC, research is always in progress.

Learn more biomedcentral.com/submissions 